\title{
Effect of Pre-Departure Culture Preparation Courses on Student Learning during International Fieldwork
}

\author{
Xiaoli Jiang \\ Faculty of Education and Arts, Federation University Australia, Victoria, Australia \\ Email: X.jiang@federation.edu.au
}

Received 23 April 2016; accepted 17 June 2016; published 21 June 2016

Copyright @ 2016 by author and Scientific Research Publishing Inc.

This work is licensed under the Creative Commons Attribution International License (CC BY). http://creativecommons.org/licenses/by/4.0/

(c) () Dpen Access

\section{Abstract}

This paper examined the effect of two pre-departure culture preparation courses on student learning during their International Fieldwork in Asia. These courses are designed to develop Anglo-European origin Australian students' knowledge, understanding and appreciation of Asian societies, cultures, etiquettes, education and political systems, together with Asian problem solving and living styles. The courses further foster student skills in intercultural communication with people from Asia. A group of students completed the training and travelled to China for fieldwork. Their evaluation and feedback, together with their written assignments, were collated and analyzed. Results indicated that the two courses are effective in assisting students' cultural adaptation to the host country environment and engaging in higher culture learning during their fieldwork.

\section{Keywords}

\section{Pre-Departure Culture Preparation, International Fieldwork, Cultural Learning and Adaptation}

\section{Introduction}

In recent years, internationalization of curriculum as a strategic development has played an increasingly important role in the Australian university sector. Geographically Australia is a country located in the Asian and Pacific region. As a result, learning and exchange with these countries are a part of Australia's strategic positioning in the region. With this view the Australian government has provided financial subsidies to support university students studying overseas. For example, the Asia Bound and New Colombo Plan (NCP) subsidies are provided by the Federal Departments of Education and Foreign Affairs and Trade. These subsidies are "intended to be transformational, deepening Australia's relationships in the region, as well as ensuring a more regionally-aware 
Australian workforce for the future” (Department of Foreign Affairs and Trade, 2016). It provides funding to enable Australian students to travel to the Asian and Pacific region of 32 countries such as China, Japan, India, Mongolia, PNG etc. The funding is projected to increase from supporting 1300 students in 2014 to 5450 in 2016 (Department of Foreign Affairs and Trade, 2016). The NCP budget has been increased from \$5.37 million in 2013-2014 to \$19.62 million in 2016-2017 and projected to be \$42.76 million in 2017-2018 (Department of Foreign Affairs and Trade, 2014).

As a result students in Australian universities have increased opportunities to study overseas. However, many of the countries Australian universities are sending students to are largely collective societies. People within these societies have very different ways of living, relating to others, being educated, perceiving the world and themselves, and especially ways of solving problems. These differences provide many challenges for Australian students in the form of culture shock. This includes complaining of hard beds, eating meat from bones, enduring very long hours of lecture style classes, experiencing ceremonies with a clear hierarchy ranking, not knowing the language, getting lost on public transport and experiencing exclusion from local communities because of a lack of skills to gain in-group status in a collective society. Some students were well prepared, enjoyed their cross-cultural challenges and took a proactive role in adapting to change and learnt a great deal. However, others who did not have any prior knowledge of the local culture struggled to make sense of the differences, experienced isolation and confusion. In one extreme case a student returned to Australia within 24 hours of arrival of her placement destination, claiming "too much difference and I don't like the place."

It would appear pre-departure preparation is critically important to student international fieldwork learning outcomes. The lack of a comprehensive pre-departure training program to prepare students for different cultural, social and living conditions could potentially generate anxiety and negatively impact on learning outcomes from the international fieldwork. In contrast, a well-designed pre-departure course(s) can promote optimal learning outcomes while overseas. This notion is based on "Flow" theory, a psychological theory that promotes optimal experiences. Optimal learning experiences require challenging activities that match student skills and enable students to have a feeling of paradox control (Csikszentmihalyi, 1992). If the challenges are far greater than a person's skills, this generally produces anxiety. If a person's skills are far higher than the challenges, this can result in boredom. When challenges are approximately equal to skill levels, a person experiences a feeling of enjoyment and involvement- "flow" (Csikszentmihalyi, 1993). Students and their self-esteem can grow as a result of their "flow" experiences. This theory helps to explain the anxiety caused by a lack of knowledge and skills on the part of students who have to deal with the challenges of a very unfamiliar cultural environment. When students are not prepared for their new destination which includes change of culture and societal behavioral norms, lack of skills to communicate and solve problems on the part of students, they can experience enormous anxiety. Learning outcomes will most likely be seriously hindered compared to those who have been prepared.

\section{Aim of the Research}

The aim of this research was to investigate the effect of two pre-departure courses, namely Asia in Focus and Intercultural Competence and Communication, as prerequisites for students' international fieldwork experience. Some of the main objectives of the two courses as follows.

\subsection{Asia in Focus}

- Gain a general understanding of Asia in terms of geography, demography and education and political systems;

- Acquire a broad knowledge of major Asian cultures and religions;

- Recognize and understand the impact of culture on individuals and their values in Asia;

- Establish analytical skills to recognize differences in culture and religions in contrast to the West;

- Acknowledge and understand the differences in culture, values, beliefs, education, and political systems between different societies in Asia and the West.

\subsection{Intercultural Competence and Communication}

- Examine the impact of cultures on diversity of behavior and communication 
- Apply theories to the analysis of cross-cultural cases

- Establish a foundation of cultural awareness from which to approach the issues posed by working internationally or working in contexts of cultural diversity

- Apply intercultural knowledge and communication skills to engage in effective communication with people from diverse cultural backgrounds, resolve conflicts raised by cultural differences

\section{Method}

This study utilized a qualitative approach to investigate and analyze the experiences of nine students, their assignments and feedback after their international fieldwork in China. All nine students, aged between 19 and 22 years old (five males and four females) were studying for their second or third bachelor degree. All of them completed the two prerequisite pre-departure preparation courses. Student opinions on the contribution of the courses to their overseas learning were collected and their assignments examined to assess their learning outcomes.

\section{Results}

The two courses introduced Asian cultures and societies, especially characteristics of a collective culture and the impact on individuals. The course Intercultural Competence and Communication introduces collective cultural associated in-group vs out-group mentality, social hierarchy/power distance, self-esteem and face work, gift giving etc. These concepts played an important part in students' understanding of the important features of collective Asian cultures and societal norms. It would appear this knowledge helped to guide student behaviors while overseas. Students also utilized these theoretical concepts to direct their observations and to analyze the cultural differences. Their successful learning is reflected in their final fieldwork reports, journal and case studies.

\subsection{Understanding Collective and Individualistic Cultures}

One of the most distinguishable cultural differences between Australia and most Asian countries is that Australia is an individualism orientated society while most Asian countries are dominated by collective culture values (Hofstede, 2001). The two prerequisite courses focus on this difference and the implications in societal norms, relevant cultural values and different ways of solving problems.

Two of the most important societal norms in Asian societies are clear social hierarchy and in-group vs outgroup. During classes students had opportunities to discuss the implications of these two norms such as relationships between parents and children, employers and employees, teachers and students, insiders (friends) and outsiders (strangers), equality and equal opportunity, family ties, friendship, nepotism, issues of implementing democracy etc. These societal norms are very different from that of Western individualistic societies and are reflected in daily life and in many protocols of the society.

\subsubsection{On Social Hierarchy and Power Distance}

Students were able to apply the knowledge re social hierarchy and power distance into their fieldwork, made sense of the very different ways of doing things and happily followed the local rules without any hesitation. In their assignments they utilized what they had learnt in the two courses and applied this to their culture learning analysis.

For example, one student wrote in his final report:

"In China particularly, titles play an important role and help reinforce the hierarchy structure so ingrained into this age-old culture. Titles go hand in hand with hierarchy and face also. For example, in Australia it is perfectly acceptable for us to call a teacher by their first name. However, in China this is completely unacceptable and teachers are addressed by their last name and followed by a title... By using these titles, you also reinforce hierarchy. By using the title fuchu zhang (副处长) or Deputy Director you will know the person is quite clearly above you and is to be treated with respect in order to give and maintain face. 'Preserving one's reputation and contributing to the reputation and prestige of others is one of the most important moral responsibilities of every Chinese' (Brown \& Brown, 2006)... The Power Distance Index/Theory (PDI) as created by Geert Hofstede reflects a country's conformity to a hierarchical structure or an equal- 
ity structure. Countries with a low power index such as Australia, aim to provide equality to all, particularly in a professional structure. However, countries with a high power index such as China are happy to accept the unequal distribution of power based on the hierarchy structure with no further questions or judgment about the system (Hofstede, 2001)."

Another student discussed the hierarchy and high power distance between teachers and students as follows:

"In Australia, lectures generally run between one or one and a half hours, whereas the lectures we had in China usually ran between two and a half to three hours. During this time there was usually a break offered, but only a short break. There was no interaction between staff and students during these lectures. Many times the teacher would ask a question and not wait for an answer but rather move on and give the answer in the same breath. We had very little chance to give opinions on matters, but rather taught what to think, not how to think. Teachers in China however like to have ultimate control of what is said and what happens in their classroom... In a high-PDI culture 'students are discouraged from asking questions because questions might pose a threat to the teacher's authority (Lustig \& Koester, 2006). In Australia, or any western institution the students would be allowed to have their say on the matter and perhaps even facilitate a discussion related to the matter with assistance of a teacher.”

\subsubsection{On In-Group and Out-Group}

One student wrote in her final report focusing on in group and out-group issue.

"An in-group is where an individual identifies as being part of a group, a member or part of a friendship group. An out-group is when an individual is not identified as being part of a group for various reasons, sometimes, based on a biased opinion of the group. In Australia we have in and out groups such as cliques and friendship groups, just as a general idea. These groups are a lot more flexible in terms of who is allowed in and how much information and personnel issues are shared amongst individuals in the group. However in China this is not the case at all, especially in a business/working environment. There are a lot of benefits that come from being in the in-group in China. We also saw the impacts of how being a part of the in-group with certain people, even with teachers, had its benefits too. Not only would you be treated in a nicer manner but you would sometimes be given extra opportunities to benefit yourself. If you were one who was in an out-group you would be able to notice the differences in how you're treated in comparison to others that are in an in-group...

Giving gifts was one of the quickest ways to getting yourself into an in-group. Talking about personnel things such as family what you study and what you want to do in the future is also another way of getting in. Even if you dress nicely or present yourself really well and you're polite and humble you're more likely to get yourself in an in-group. To get through the barrier and into the inner group there are a few ways to accomplish this... Another factor that helped with getting into the inner group is of course gift giving. Gift giving had quite an impact on a person or group as it showed your gratitude and thanks. It is also a way of giving someone or a group face as well...”

\subsection{Knowledge on Externally Evaluated and Internally Evaluated Self between Different Cultures}

One of the most important parts of the course Intercultural Competence and Communication is to introduce to students ideas re how culturally different when it comes to how we evaluate out self. In general, it has been widely accepted that the self in collectivist cultures is enmeshed and conceptualized, so that self-esteem is more interdependent and based on external evaluation. The self in individualistic cultures is more self-contained, isolated and clearly bounded. Self-esteem is likely to be more independent and internally evaluated (Tafarodi \& Lang, 1999).

\subsubsection{On "Face"}

The external evaluation of self-esteem is clearly expressed by "face" in Asian societies. Westerners normally have little understanding of this matter. However, the prerequisite courses introduced the issue of face and its relationship with self-evaluation. Students started to understand how important face is to Asian people. They 
appear to pay special attention to the matter, especially when they were in an Asian country and working with the locals. One student wrote in her report:

"The face negotiation theory explains how one's self esteem can increase or decreases according to the actions of those around them (Ting-Toomey \& Kurogi, 1998). In many Asian societies, including China, the idea of 'face' is an integral part of everyday life. Face can be gained by achievement recognition, receiving gifts and compliments. However, face can be lost in various ways including public embarrassment, lack of achievement and by being refused or said 'no' (Ting-Toomey \& Kurogi, 1998).

During our time with our Chinese friends, it seemed that they received more confidence and a boost in social standing just by interacting and being friends with the white foreigners. As per our upbringing, we Australian students focused on complimenting our new friends on their achievements and attire, not criticizing them on how they could be or look better. If needed, we used constructive criticism by combining praise with a suggestion so that person did not feel targeted."

\subsubsection{On Gift Giving}

Gift giving is a pronounced Asian etiquette when people meet each other for the first time or friends and family members meet after a period of separation. The quality and quantity of the gifts are just as important because they have a close connection with face giving or maintenance of face and could make or break a relationship or business deal. One student analyzed this phenomenon in his report:

"Gifts are a sign of courtesy in China. The word for courtesy in Chinese, li (礼) is the first character in the word for gift li wu (礼物) (Brown \& Brown, 2006). Gift giving is way to further give face to your host. Chinese people are practical when it comes to gifts, they prefer something they can use. This is why before we departed a lot of thought went into the gifts. Whilst practicality was important, hierarchy was even more so. We had to gift appropriately according to status. We gifted Director XXX with two packets of fish oil tablets, Teacher XXX with perfume made in France, and Vice President XXX and Teacher XXX with plates adorned with Australian patterns. By giving Director $X X X$ some fish oil tablets as a gift, we managed to get some other activities and lunches added to our schedule. We were taken to OCT at night, had a lunch in a VIP room and had coffee at East Campus, amongst other things. The director thought highly of these gifts and believed they were of the highest quality and must have been expensive because they're from Australia.

Gift giving allows one a small taste of the in-group. By following the custom of li wu or gift giving, one is automatically working their way into the in-group. Being the student who actually gave the gifts to those above me in China allowed me an instant connection over everybody else."

There are many more similar analysis in students' assignments. They are fascinating to read and reveal students' in-depth understanding of Asian (in this case Chinese) culture values and the reasons behind the cultural differences. Due to the word limit of this paper, only a small selection of student work can be presented. However, the nine students participated in an anonymous survey. The survey revealed that $87.5 \%$ of the students believed that the course Intercultural Competence and Communication had been extremely helpful to their trip preparation and adjustment to cultural differences during the trip. The remaining $12.5 \%$ believed the course was helpful. For the course Asia in Focus, all students believed it was helpful, in which 37.5\% thought it extremely helpful.

Students articulated in their reports and feedback:

The course "Asia in Focus was a very interesting and in-depth class that provided a great insight into Asian Societies such as China and explained the history of China... It helped in the preparation of 'cultural shock"”. "It provided a basis for further learning." It gives "historical background to enhance understanding." "Provided us with general information on China and its culture."

"The prior learning undertaken by the group before our departure was absolutely invaluable. The Intercultural Competence and Communication class provided us with insight into varying situations which could be easily misinterpreted if not understood beforehand. It allowed us to recognize the differences in Eastern and Western cultures so we could communicate without offending anyone. This class needs to remain a prerequisite for the International Experience course, without it I believe we would have offended 
many people."

The course (Intercultural Competence and Communication) "was crucial in order to understand some of the difference in Chinese culture, for example, the concept of face." "Very useful for dealing with cultural differences both in social and educational."

"The class (Intercultural Competence and Communication) provide the core to establishing efficient and culturally aware communication between us Australian students with the Chinese people. The class give us knowledge into Eastern and Western philosophies which guide people's lives and acknowledged the differences that must be respected. Without such a class, us Australian students would never have been able to make a transition into Chinese customs or society and would not have had a pleasant experience. This class was adequate in preparing us for what we should expect."

"I found that this course (Intercultural Competence and Communication) was surprisingly helpful and I recommend it to other students wishing to travel to an Asian country."

It should be noted that within this group of nine students, two have a medically diagnosed anxiety disorder. However all students returned from the trip with very positive experiences and enhanced learning outcomes. The extensive preparations for the trip helped to make this possible.

\section{Conclusions}

It would appear that the pre-departure courses are effective in preparing Anglo-European Australian students for their fieldwork in Asian countries because the major differences have been introduced and the unexpected events come as no surprise. Students developed knowledge, understanding and appreciation, together with skills to meet the challenges of a different culture in studying, living and solving problems. It is apparent that students had a feeling of being in control because of their detailed preparation. Questions were answered and a potentially different problem solving process was rehearsed. As a result they were able to enjoy the trip much more and experience the differences with an understanding of the social and cultural background. Their learning of the local culture rose to what is considered to be "genuine higher learning" that subverts the taken-for-granted world of others (Institute for the Advancement of University Learning, University of Oxford, No Date). The students' intellectual and imaginative powers were developed. Their understanding and judgment, their problem-solving skills, their ability to communicate and to see relationships in a broader perspective were vastly improved. Their enquiring, analytical and creative minds were stimulated, and encouraged to provide independent judgment and critical analysis.

However, it should be acknowledged that the sample size of this study is not large. Further research is required to gain additional insight into the effect of the pre-departure preparation program.

\section{References}

Brown, J., \& Brown, J. (2006). China, Japan, Korea Culture and Customs (pp. 41-57). North Charleston, SC: BookSurge, LLC.

Csikszentmihalyi, M. (1992). “Flow”: The Psychology of Happiness (p. 6). London: Rider.

Csikszentmihalyi, M. (1993). The Evolving self: A Psychology for the Third Millennium. New York: HarperCollins.

Department of Foreign Affairs and Trade, Australian Government (2016). New Colombo Plan Fact Sheet. https://dfat.gov.au/people-to-people/new-colombo-plan/resources/Documents/new-colombo-plan-fact-sheet.pdf

Department of Foreign Affairs and Trade, Australian Government (2014). New Colombo Plan Guidelines Mobility Program, 2015 Round.

http://dfat.gov.au/people-to-people/new-colombo-plan/mobility-program/Pages/mobility-grants-faq-2014-pilot-phase.aspx

Hofstede, G. (2001). Culture’s Consequences: Comparing Values, Behaviors, Institutions, and Organizations across Nations (p. 215). Thousand Oaks, CA: Sage Publications.

Institute for the Advancement of University Learning (No Date). Higher Education and Higher Learning. University of Oxford.

https://www.learning.ox.ac.uk/media/global/wwwadminoxacuk/localsites/oxfordlearninginstitute/documents/supportresou rces/lecturersteachingstaff/resources/resources/Higher_Education_and_Higher_Learning.pdf

Lustig, M., \& Koester, J. (2006). Intercultural Competence: Interpersonal Communication across Cultures (5th ed., p. 125). 
Boston, MA: Pearson and AB.

Tafarodi, R. W., \& Lang, J. M. (1999). Self-Esteem and the Culture Trade-Off. Journal of Cross-Cultural Psychology, 30, 620-639. http://dx.doi.org/10.1177/0022022199030005004

Ting-Toomey, S., \& Kurogi, A. (1998). Facework Competence in Intercultural Conflict: An Updated Face-Negotiation Theory. International Journal of Intercultural Relations, 22, 187-225.

http://dx.doi.org/10.1016/S0147-1767(98)00004-2 